\title{
SMALL FIRM INTERNET ADOPTION: OPPORTUNITES FORGONE, A JOURNEY NOT BEGUN
}

\author{
By \\ Colin Jones*, \\ Dr Rob Hecker
}

And

Dr Peter Holland
Colin Jones

University of Tasmania

School of Management

PO Box 152-16

Sandy Bay

Tasmania 7005

Australia

phone: +61 (0) 362262826

fax: +61 (0) 362262808

Colin.Jones@utas.edu.au

* = Contact Author

Word Count: 5377
Dr Rob Hecker

University of Tasmania

School of Management

PO Box 152-16

Sandy Bay

Tasmania 7005

Australia

phone: +61 (0) 362261174

fax: +61 (0) 362262808

Rob.Hecker@utas.edu.au
Dr Peter Holland Monash University

Department of Management

Faculty of Business and

Economics

Wellington Road

Clayton

Victoria 3800

Australia

phone: +61 (0) 399052329

fax: +61 (0) 399055412

Peter.Holland@BusEco.monash.edu.au 


\title{
SMALL FIRM INTERNET ADOPTION: OPPORTUNITES FORGONE,
}

\section{A JOURNEY NOT BEGUN}

\begin{abstract}
This paper explores the endeavours of five small firms to develop web-based commerce capabilities within their existing operations. The focus is upon the strategic acquisition and exploitation of knowledge which underpins new value creating activates related to web-based commerce. A normative web-based commerce adoption model developed from a review of the extant literature related to electronic marketing, entrepreneurship, and the diffusion of new innovations was empirically tested. A multiple case study design enabled the exploration of contemporary marketing and entrepreneurship issues within the real life context of five small firms. The model aimed to emphasis best-practice adoption methods emphasizing the value of a firm's market orientation and entrepreneurial capabilities. A preliminary test of the model's theoretical contentions lent support to its overall focus, but found that the firm's existing learning capabilities were diminished during the adoption of web-based commerce, and that a lack of vision and prior knowledge produced sub-optimal adoption outcomes.
\end{abstract}

KEY WORDS: Web-based Commerce, Small Firms, Internet Adoption, Market Orientation, and Entrepreneurship

\section{INTRODUCTION}

The advent of the ubiquitous Internet has delivered a plethora of latent opportunities for small firms and/or entrepreneurs to creatively engage in new value creating activities. As at July 2001, 75\% of Australian small firms, defined as having 19 or less employees (McLennan, 1999) were connected to the Internet (Yellow Pages Business Index, 2001). Despite the high 
Internet implementation rates by Australian small firms, only $27 \%$ utilise the medium to advertise their products online, only $19 \%$ accept online orders, and a mere $13 \%$ offer an online payment service for their customers (Yellow Pages Business Index, 2001). This is in stark contrast to Australian small firm usage of the Internet for e-mail (82\%) and general research purposes (65\%) (Yellow Pages Business Index, 2001). Interestingly, and despite the apparent low actual usage rates of activities that could create new value for small businesses, $62 \%$ of Australian small firms yet to introduce the Internet into their operations, stated their imminent intention to become an on-line business (Yellow Pages Business Index, 2001). Given these base statistics, there appears to be a significant discrepancy between the levels of commercial Internet adoption and its contribution to incremental firm growth.

Although the potential benefits of web-based commerce are well documented e.g. new markets and revenue sources (e.g. Armstrong and Hagel, 1996; Hamill, 1997; Hoffman and Novak, 1997), there is a paucity of research dealing with the generic issue of how to effectively implement web-based commerce into a small firm’s operations. Consequently, this paper contributes to the literature through the development of a best practice adoption model that is developed with reference to the dynamic relationship between entrepreneurship and market-orientedness (Slater and Narver, 1995). The advent of the Internet provides a research opportunity to examine the actual behaviours of small firms against a normative adoption model that is driven by a vision of the future, access to specialised knowledge and the coordination of firm resources.

Six specific areas deemed central to the adoption and effective implementation of web-based commerce were identified within the extant literature. These areas, integral to the proposed normative web-based adoption model and to be discussed in the following section, are as 
follows; 1) Web-based Commerce Adoption Drivers; 2) Market Orientation; 3) Cooperative Behaviours; 4) Web-based Business Models; 5) Value Chain Reconfiguration; and 6) Webbased Value. Through a synthesis of the literature, a normative and generic adoption model for small firm web-based commerce was developed (see Figure 1) accounting for the critical integration of existing and future knowledge for opportunity identification and exploitation (Shane and Venkataraman, 2000).

\section{Take in Figure 1}

\section{PROPOSED NORMATIVE WEB-BASED COMMERCE ADOPTION MODEL}

The model sought to combine components available to small businesses, therefore increasing possible acceptance of the model beyond specific industry characteristics. As such, this research sought to make two specific contributions. Firstly, to provide a generic adoption model for small firms with regard to the strategic implementation of web-based commerce into their overall business strategy. Secondly, to identify sources of potential difficulty and inefficiency in the actual implementation of a web-based commerce strategy for small firms from an entrepreneurial marketing perspective (Collinson and Shaw, 2001).

\section{Web-based commerce adoption drivers}

Previous research into small firm adoption of web-based commerce has identified the medium's perceived benefits as the primary motivator (e.g. Poon and Strom, 1997; Poon and Swatman, 1999). Acknowledgment of potential opportunity gains forms the basis of an evision. However, Rogers (1995) argues that successful adoption of complex innovations requires a knowledge base beyond 'mere awareness' of perceived benefits. During Stage One of the of the adoption model (see Figure 1), it is predicted that firms gain an awareness of the 
perceived benefits of web-based commerce through exposure to the hype that surrounds the medium, and through change agents (such as Internet service providers [ISPs]) who promote its virtues.

However, complex innovations such as the Internet, require a knowledge base far exceeding awareness or general knowledge to both appreciate its possible application and reduce the possibility of misuse. Rogers (1995) states that adopters must acquire a higher knowledge base comprising 'how to' and 'principles’ knowledge. 'How to’ knowledge provides webbased commerce adopters with an understanding of how to use the innovation effectively, and 'principles' knowledge refers to the theoretical underpinnings of the innovation. The suggestion being that while awareness of the innovation may provide a possible 'e-vision' (Sawhney and Zabin, 2001), it is the acquisition of 'how to' and 'principles' specialised knowledge that underwrites its successful implementation (Rogers, 1995; Shane and Venkataraman, 2000).

\section{Market Orientation}

The literature supports firm reliance upon market orientation during the adoption of technological innovations to enhance organisational learning (Glazer, 1991; Hoffman and Novak, 1997; Morgan, Katsikeas and Appuh-Adu, 1998). Therefore, during Stage Two (see Figure 1) market-oriented firms should access the required 'how to' and 'principles' specialised knowledge needed to successfully adopt web-based commerce. In proposing market orientation as a defendable resource system, Hunt and Morgan (1995:11) define a firm’s market orientation to be: 
(1) the systematic gathering of information on customers and competitors, both present and potential, (2) the systematic analysis of the information for the purposes of developing market knowledge, and (3) the systematic use of such knowledge to guide strategy recognition, understanding, creation, selection, implementation, and modification .

Despite some reservations in terms of the ability of consumers to articulate latent needs (Wrenn, 1997; Connor, 1999) and of firms to easily interpret such needs (Baker and Sinkula, 2002), market-oriented firms are assumed to have unique sense and respond capabilities (Slater and Narver, 1995). The seminal work of Hoffman and Novak (1997) associates market-oriented firm behaviour with the development of a future web-based competitive advantage due to its ability to provide firm access to customer, market and technology intelligence. Glazer (1991) also proposed the use of a firm's market orientation to facilitate increased access to intelligence in information-intense markets. A complementary relationship is posited to exist between the constructs 'market orientation' and ‘entrepreneurship’ (Slater and Narver, 1995). Through an understanding of existing customer needs, entrepreneurs working with lead-users are predicted to be able to better evaluate the potential value of identified opportunities. As a result, the most fundamental entrepreneurial and marketing functions, positioning and segmentation (Lodish, Morgan and Kallianpur, 2001) are maximised. The firm is able to match a potential value creating opportunity to the target market(s) with an appreciation of why those particular consumers may value their future offerings.

Entrepreneurship, defined as "the discovery and exploitation of profitable opportunities" (Shane and Venkataraman, 2000:217), is also viewed as a resource capable of supporting a 
competitive advantage. Alvarez and Busenitz (2001) argue that it is an entrepreneur's cognitive ability that allows situations to be framed in an opportunistic manner leading to the subsequent coordination of other knowledge generating resources such as a firm's market orientation. Therefore it is posited that the combination of the two resources potentially leads to faster learning and superior returns from innovative products and processes. In summary, Stage Two suggests that without access to specialised knowledge of customers, technology and the marketplace, the firm's adoption of web-based commerce will be less than optimal. Web-based commerce requires an expanded knowledge base and firms with a high degree of market orientation will be able to access essential information sources.

\section{Cooperative Behaviours}

Stage Three (see Figure 1) proposes the engagement of cooperative behaviours to share information through which the business's knowledge base is expanded. McWilliams and Gray (1995) and Lado, Boyd and Hanlon (1997) propose the use of cooperative strategies (e.g. logistics, payment \& referrals) to overcome resource weaknesses that restrict the implementation of resource strengths. Small firms seeking and/or in the possession of 'how to' and 'principles' specialised knowledge may require assistance to access the benefits of web-based commerce due a possible lack of expertise, time or financial resources. Therefore, in the absence of technical 'web-based commerce' knowledge, small firms need to access knowledge experts (Kirzner, 1979) and apply their existing entrepreneurial knowledge to maximise the potential returns (Alvarez and Busenitz, 2001) from their adoption of webbased commerce.

Hoffman and Novak (1997) propose the development of a cooperative rather than competitive approach to competitors to maintain a market orientation during web-based 
commerce adoption. Complementary relationships with other firms are recommended to create additional value through new and innovative resource structures (Brandenburger and Nalebuff, 1995). Rayport and Jaworski (2001) also support the use of partnerships and strategic alliances, which allow web-based firms to focus on their core competencies while developing resource clusters that enhance overall firm capabilities. However, during this process, the firm's value chain and business model may be subject to a process of reconfiguration (Timmers, 1998), requiring increased knowledge of customers' desired benefits, technological capabilities and markets (Rayport and Jaworski, 2001).

Stage Three proposes the use of the firm's market orientation to share information and acquire new knowledge of customer needs, technological potential, and marketplace opportunities. This may increase the ability to acquire the 'how to' and 'principles' specialised knowledge required for the adoption of web-based commerce. Cooperation at this stage, especially for small firms, is vital given that the acquisition of information for webbased commerce may well represent a novel and therefore challenging area of knowledge development with regard to a firm's absorptive capacity (Cohen and Liventhal, 1990). Recently reconceptualized by Zahra and George as "a set of organizational routines and processes by which firms acquire, assimilate, transform, and exploit knowledge to produce a dynamic organizational capability” (2002:186), the presence of potential absorptive capacity would be indicated by the intensity, speed and direction in which firms search for external knowledge. The existence of entrepreneurial/market-oriented capabilities may provide the initial drive for firms to increase their existing knowledge base to enable development of web-based commerce. 


\section{Web-based Business Models}

As a result of additional cooperative strategies, two issues related to the firm's business model/s arise. Firstly, the introduction of new firm strategies will require consideration of the existing operating structures, and secondly, the potential reconfiguration of the value chain may impact on a firm's ability to access vital sources of intelligence. Stage Four (see Figure 1) contends that as strategy changes, so must structure (Mintzberg, 1990), and the firm's market orientation is the key resource system upon which the new business model is based.

Rayport and Jaworski (2001) state that a high quality web-based business model should meet the following criteria; it must be unique, provide links between capabilities and benefits, support links between firm activities and capabilities, be mutually reinforcing, provide a link between the physical world and the virtual world, and lastly, the resource must be capable of supporting a sustainable advantage. As such, a firm's market orientation may potentially provide an efficient resource to small firms whom typically have scarce resources (Chappell and Feindt, 1999) and simple operating structures (Peterson, 1989; Sanchez, 1997; Chau and Pederson, 2000).

Consequently, such a web-based business model would be well placed to use market intelligence to develop capabilities to support the value propositions so central to its function. Stage Four illustrates that as knowledge is gained and used cooperatively, the firm's structure is altered to accommodate and support new firm capabilities. Therefore, knowledge and the coordination of the resources are the focal drivers of business model transformation. 


\section{Value Chain Reconfiguration}

Stage Five (see Figure 1) proposes the introduction of new value creating activities to satisfy the identified desired benefits of the target market/s. In line with market orientation theory, the challenge for firms during the introduction of web-based commerce, is to remain connected to customers and responsive to market opportunities (Day, 1999). Under conditions of technological change, there is a greater likelihood that the link between firm offerings and customer needs may become divergent (Slater and Narver, 1994; Enders and Jelassi, 2000). To develop value offerings that complement the business model, Timmers (1998) and Afuah and Tucci (2001) argue for the reconfiguration of the traditional value chain (Porter, 1985) to access to new sources of web-based value.

Sawhney and Zabin with reference to Hertzberg's (1966) classic hygiene-motivation theory note the significant challenge that confronts firms adopting web-based commerce. They liken the hygiene factors to "stay-in-business" initiatives i.e. knowledge management processes, and the motivation factors to "destroy-your-business" initiatives i.e. "the development of new revenue sources through changing the mechanisms for value creation” (2001:32). Therefore the development of "deep insights into trends in technology, demographics, regulation, and lifestyles that can be harnessed to rewrite industry rules and create new competitive space” (Hamel \& Prahalad, 1994:73) is the primary role for a firm’s entrepreneurial and marketbased resources.

The model thus far suggests that market-oriented firms, who reconstruct their value systems, may create value through the alignment of business strategy and structure with an explicit understanding of the buyers of their offerings (see Drucker, 1985; Slater and Narver, 1998). During such a process, business model development may liberate 'trapped value' i.e. value 
gained from market and value system efficiencies, and/or introduce 'new-to-the-world value' i.e. new value through customisation and personalisation (Rayport and Jaworski, 2001). In summary, the model assumes the firm has now acquired 'how to' and 'principles' specialised knowledge through its prior foresight and market orientation, identifying desired customer benefits which require new firm capabilities, resulting in the need to reconfigure the value systems, to access new web-based value.

\section{Web-based Value}

Within the normative adoption model's development so far, the firm's entrepreneurial and market-oriented behaviours are posited to be central to developing a web-based value proposition. That is, in terms of the development of an e-vision, firm capabilities through cooperative actions and access to new value creating activities/architecture are seen as supplementing the established activities of the value chain. Four sources of web-based value have been identified (Amit and Zott, 2001) as efficiency (e.g. reduced transaction costs), complementarities (e.g. the integration of physical and virtual assets), lock-in (e.g. forms of customisation and personalization that increase switching costs) and novelty (e.g. stimulating new ways to conduct transactions).

The value sources are dependent upon two important factors. Firstly, a synergistic relationship exists between the sources requiring a need to develop all four to enhance the value of each individual source. Secondly, their contributions to a competitive advantage are premised upon mutual gains between the firm and customer. Therefore, all are dependent on increased levels of strategic customer, market and technology knowledge. Again it is the relationship between entrepreneurship and market orientation that acts to envisage the future, access required knowledge and guide strategy implementation. Given the noted discrepancy 
between Internet implementation and its integration into activities supportive of incremental growth, an opportunity exists to empirically test the developed normative best-practice adoption model.

\section{RESEARCH METHOD}

Due to the exploratory nature of the research, a multiple case study design (Yin, 1994) was used to facilitate in-depth interviews with five small Tasmanian firms to explore the adoption of web-base commerce within a real-life context. The research aims were to observe the degree of congruence between firm adoption of web-based commerce and the proposed model, and to identify difficulties experienced and value created. Given the proposed importance of market orientation to the adoption model's construction, Pelham and Wilson's (1996) small and medium firm-specific market orientation scale was used to measure the degree of pre- (traditional commerce) and post-adoption (web-based commerce) market orientation. A judgemental sampling approach (Babbie, 1999) enabled the cases to be selected via a selection criterion that enhanced the research aim of observing the influence of an intangible firm resource (market orientation) during the adoption of web-based commerce and the development of new value creating activities. The firms met the following criteria: all had served domestic, interstate and international markets in excess of five years, web-based commerce supplemented their existing operations, and their web site facilitated customer service, marketing communications and the exchange of a physical product.

\section{THE FINDINGS}

The findings of this preliminary research are that the five Tasmanian firms did not follow the normative adoption model arising from the synthesis of the extant literature. There was however, support for the theoretical contentions of some discrete stages within the model. 
Most notably, the influence of perceived benefits. Table 1 illustrates that the relative degree of market orientation measured (with the exception of one) was less for web-based commerce in contrast to traditional commerce, with results ranging from $-2.25 \%$ to $-28 \%$.

\section{Take in Table 1}

The presence of entrepreneurial and market-oriented behaviours was not evident in any of the firms' observed web-based commerce behaviours. The firms did not access the 'how to' and 'principles' specialised knowledge essential to the development of a web-based commerce competitive advantage. Articulation of what they were trying to achieve, with whom and for what reward was not forthcoming. From an entrepreneurial perspective, three of the cases clearly approached their adoption from a very experimental perspective, but did not demonstrate any learning outcomes from the experience. The one firm that did demonstrate market-oriented behaviours, albeit three years post adoption, engaged in cooperative strategies and business model development and were able to clearly articulate the needs and wants of their web-based customers.

Across all the firms, resource constraints related to time and finances were offset through the acceptance of adoption incentives/assistance during their initial adoption of web-based commerce development. However, the most prevailing difficulty experienced across the firms was access to information sources through which 'how to' and 'principles' specialised knowledge could be obtained and incorporated into the development of web-based commerce. The firms relied upon ISPs/advisers to introduce 'knowledge'. However the ability of local ISPs/advisers to act as 'technology linkers' was clearly beyond the scope of their capabilities, thereby providing tacit support for Plume (2001), who notes a significant 
challenge confronts web-based commerce in the form of knowledge integration. Specifically, this challenge is to the ability of firms (or external persons, such as ISPs) to successfully integrate traditional marketing practices with new technological opportunities to create value that is supportive of a sustainable competitive advantage. The dependence upon the existing structural architecture appeared to dampen the desire to develop new value creating activities.

Despite the firms demonstrating the capability to develop a competitive advantage in traditional commerce through the involvement of customers and channel members, such parties were reduced to mere spectators during their initial development of web-based commerce. It was observed in one case (which also demonstrated superior market-oriented behaviours) that when customers were transformed from spectators to participants, an increased understanding of the potential of web-based commerce did in fact occur. However, the web-based value observed (i.e. communication and research efficiencies), was internalised within the firms, not shared with customers or channel members. Learning was observed to be adaptive and therefore not spanning the firm's boundaries, an essential for generative learning and an expected outcome for entrepreneurial and market-oriented approaches. While web-based value received exceeded the perceived cost of adoption (i.e. time and effort), it was insufficient to lay the foundation to a future competitive advantage.

\section{DISCUSSION}

This research sought to identify possible reasons for the marked discrepancy between small firm implementation of web-based commerce and its ability to create incremental value for firms and their customers. The research findings identify several major implications for the discipline of marketing and small firm practitioners engaged in web-based commerce. Firstly regarding the discipline of marketing, the application and engagement of a firm's market 
orientation, its nature, measurement, and value during web-based commerce adoption require further consideration by future researchers. Secondly, the unsuccessful acquisition, and therefore conversion of adoption information into adoption knowledge, by small firms represents a major hurdle to the optimal adoption of web-based commerce.

\section{The Role of Market Orientation}

As the central driver of the adoption model, market orientation was argued to be responsible for developing a rich knowledge base, reflective of customers needs (expressed and latent), marketplace opportunities, and the technologies that will connect the entities. Without such knowledge, firms may not sense the desired benefits of their present and future customers required to identify value-creating activities supportive of a competitive advantage. A clear discrepancy was obtained between recorded market orientation measurements using Pelham and Wilson's (1996) scale and observations of actual firm behaviours. The firms, while claiming to have developed strategies based upon an understanding of their customers' webbased behaviours (i.e. the Pelham and Wilson survey), demonstrated no strategic actions related to developing knowledge of the customers, technologies and markets associated with web-based commerce (i.e. actual observations). The first concern relates to the application of the firm's market orientation.

As a pre-existing intangible resource, a firm's market orientation must be maintained and applied to contribute value to the firm. Market orientation, intrinsically reflective of a firm's culture (Hunt and Morgan, 1995), is a source of value through application, rather than merely through possession (Prahalad and Hamel, 1990). The absence of observable market-oriented behaviours restricted the empirical testing of the normative adoption model's application. The apparent failure to transfer the observed market-oriented behaviours from traditional 
commerce to web-based commerce would appear related to the firms' lack of direction and knowledge in developing web-based capabilities.

The non-engagement of market orientation and thus a lack of learning behaviours would appear related to a conspicuous absence of entrepreneurial purpose. No evidence was observed with regard to awareness of opportunities associated with the adoption of webbased commerce. Rather, the adoption of web-based commerce appeared more related to adoption incentives from ISPs and advisers. An over reliance on external parties to import knowledge has in this instance, made the need for e-vision and associated learning processes redundant. Clearly the firm's internal foresight, strategy development and learning has been hijacked by external parties whose primary purpose should be have been the implementation of the former activities. Consequently, while the firms professed to have adopted web-based commerce, in reality, their journeys had hardly begun.

The very nature of a firm's market orientation may well be challenged by new learning processes inherent in web-based commerce (Min, Song, and Keebler, 2002). Slater (2001) suggests that a firm's established market orientation must evolve to ensure greater market sensing in the face of significant market change. Slater notes that a future challenge for firms desirous of developing an e-market orientation is to stay connected to their customers. This echoes the literatures consistent proclamation for market-orientation of 'listen to the customer, understand the customer, and provide a solution for the customer'. This appears predicated on market orientation being dependent upon a one-way linear relationship between customers, marketing, and the technologies employed to provide solutions. 
However, the research findings lend support to the proposition of Wrenn (1997) that the development and application of the market orientation construct may not be so straightforward. The firms found difficulty gaining access and understanding of their customers' needs and wants. As such, the accepted interpretational role of marketing simply did not occur. Consequently technologies, be they products, processes, or a combination of both, did not eventuate to solve customer needs and wants. Wrenn further asserts that a nonlinear relationship between the customer, marketing and technologies (Kotler, 1997) is required to translate technological attributes into customer benefits to sustain a market orientation during times of complex technical change (i.e. the Internet). The suggestion is that a far more dynamic role for marketing may be required to maintain or establish marketoriented behaviours within an environment influenced by rapid technological change.

Significantly, this may suggest an increased importance on the firm's entrepreneurial capabilities to visualise the potential benefits that would precede the coordination of specific market-oriented learning behaviours. Or, in the event that an e-vision is not readily forthcoming, an increased reliance on identified lead users to assist co-develop an e-vision. However, the activities of one firm over the eight months preceding the data collection period provides evidence of the valuable role customers contribute to market-oriented firms in their adoption of web-based commerce. The firm developed close relationships with web-based customers in the North American market. In addition to being the only firm to record an increased web-based market orientation, they were also the only firm to articulate a clear understanding of their web-based customers' preferences and buying behaviour, market opportunities and the application of technology for web-based commerce. 
Along with an increased web-based market orientation (i.e. the Pelham and Wilson survey), obvious market-oriented behaviours were observed. For example, the firm developed a database through which valuable customer information of preferences was recorded and regularly updated, providing the firm with a longitudinal record for customer profiling. The firm also engaged in cooperative strategies to acquire 'how to' knowledge through sharing the cost of technical training. As such the firm's adoption behaviours (albeit three years post adoption) provide partial support for Stages Two and Three. The firm has used marketoriented behaviours to acquire a greater understanding of their customers and used cooperative practices to enhance such behaviours.

Finally, the case method produced an inconsistency between measured and observed marketoriented behaviours. The recorded levels of web-based market orientation appear to reflect anticipated future actions, rather than actual behaviours. The firms appeared unable to separate their beliefs concerning what they actually do in a traditional sense compared to what that actually do in a web-based sense. Given the prominence of quantitative methods that employ surveys to measure market orientation, the findings cast a shadow over the accuracy and reliability of such methods. The findings lend support to the contentions of Rouse and Daellenbach (1999) that a greater understanding of the actual contribution of such intangible firm resources should occur from within, rather than outside, firms. Given that small firm marketing practices are in general more simplified in comparison to larger firms (Stokes, 2000), a more qualitative approach would enable future research to capture a more realistic picture of small firm behaviour with regards their actual marketing practices. 


\section{Knowledge acquisition and development difficulties}

A recurrent process throughout the web-based adoption model is the acquisition of market intelligence related to target markets, marketplaces and technologies and its conversion into specialised knowledge. With the exception of one firm's delayed behaviours, the firms have not acquired such information, and therefore lacked a sufficient knowledge base upon which to build a web-based commerce platform. As previously discussed, the firms did not utilise their observed traditional market-oriented behaviours during adoption of web-based commerce.

Three interrelated factors appear to have contributed to the firm's insufficient knowledge base. Firstly, an inability to visualise new sources of value and alternative structures that would be complementary or superior to their existing value systems. Secondly, an over reliance upon their ISPs/advisors to perform a technology linking role, and therefore an apparent lack of enthusiasm to explore the new web-based landscape themselves. Lastly, the firm's individual lack of absorptive capacity appears to have hampered what little efforts have been made to learn about web-based commerce opportunities.

\section{The lack of vision}

Sawhney and Zabin (2001) posit that many firms may be constrained by assumptions, inherited from their past that restrict their view of the future. Despite the literature's expectation that entrepreneurial and/or market-oriented firms will challenge past assumptions through generative learning processes (Slater and Narver, 1995), an e-vision was not visualised during adoption. As such, no consideration was given to visionary architectural change, but rather, reliance was placed upon modifying the past. The findings suggest ignorance as to the need for 'how to' and 'principles' specialised knowledge. 
Overall the initial approach appears very much a case of “if you don't know where you're going, any road will take you there” (Sawhney and Zabin, 2001:11). The findings are consistent with the conclusions of Chaston, Badger, Mangles, and Salder-Smith, (2001) that perhaps small firms underestimate the need for planning prior to adopting web-based commerce. It also perhaps serves to highlight the potential difficulty of juggling dual entrepreneurial perspectives for traditional and web-based commerce. The firms' showed no propensity to explore “destroy-your-business” initiatives, but rather remained guided by "stay-in-business" initiatives (Sawhney and Zabin, 2001:32) demonstrating a lack of motivation to transform their traditional commerce activities beyond superficial refinement (e.g. e-mail and information search capabilities).

\section{The quasi-technology linker}

The firms relied heavily on external ISPs/advisers to facilitate the development of web-based commerce at the expense of using their own knowledge of existing customers needs. Subsequent interviews with the relevant ISPs confirmed that they had neither the ability, nor the desire to provide 'how to’ and 'principles' specialised knowledge. Therefore, the potential opportunity to co-create a value proposition derived from customer participation was lost, along with the value of the firm's pre-existing market orientation. It would seem that in the absence of a clear e-vision, empowering customers as co-architects of future value would be beneficial to identifying potential new value. This would allow the ISPs to implement what is possible from an architectural perspective, rather than what is current thinking from an engineering perspective. 


\section{Individual absorptive capacity}

Absorptive capacity, previously defined as the "routines and processes by which firms acquire, assimilate, transform, and exploit knowledge to produce a dynamic organizational capability” (Zahra \& George, 2002:186), or simply, the ability to acquire and strategically use 'how to' and 'principles' specialised knowledge. The firms lacked intensity, speed, and direction in their observed efforts to acquire external knowledge to the detriment of their ability to acquire 'how to' and 'principles' specialised knowledge. This appears to indicate the difficulty in transferring a market orientation from traditional to web-based commerce without a guiding e-vision. It also perhaps reflects the difficulty of acquiring knowledge from such a novel and challenging domain without maintaining existing entrepreneurial capabilities. Perhaps an inability to receive or quantify a probable future cash flow from adopting web-based commerce, an important factor in small firm marketing (Carson, 1998), reduces the motivation to acquire specialised knowledge.

\section{CONCLUSION}

This research, through the development of a normative web-based adoption model, sought to examine the influence of a firm's market orientation to assist in the development of a webbased competitive advantage. It was theorised that market-oriented firm behaviours were essential requirements to optimising the development of web-based commerce in small firms within which resource constraints (i.e. time, finances and knowledge) commonly occur. That only one firm was satisfied with their adoption of web-base commerce, and that they were the only firm to exhibit market-oriented behaviours (albeit three years post adoption), provides partial support for the role of market orientation during web-based commerce adoption. 
Without engaging entrepreneurial (i.e. identifying opportunities and resource coordination) and market-oriented behaviours (i.e. the gathering, dissemination and strategic use of information), the value of both resources is significantly decreased. Mere prior possession of the resources is not sufficient to contribute future value, they must be engaged to ensure specialised knowledge is obtained and disseminated within the firm and strategic partners. As such, a failure to identify web-based commerce value creating opportunities would seem detrimental to the optimal adoption of web-based commerce.

This research has highlighted the difficulties in maintaining and/or developing entrepreneurial marketing behaviours in environments influenced by rapid technological change. Greater appreciation is required within the extant literature of the difficulty of using traditional marketplace market-based assets to support the development of web-based commerce. Small firms make a significant contribution to the Australian economy (Gare, 2001) and other world economies. It is therefore imperative further research examine the opportunity recognition and learning processes that contribute to the development of specialised knowledge through which small firms can exploit new web-based value creating activities. At present, it would appear small firms may be delaying departure for their webbased commerce journeys due to a lack of foresight, and therefore knowledge capital. As a result, the potential entrepreneurial rents from the adoption of web-based commerce may remain elusive.

\section{REFERENCES}

Afuah, A. and Tucci, C. L. (2001) Internet business models and strategies, Sydney, McGrawHill Irwin.

Alvarez, S.A. and Busenitz, L.W. (2001) 'The entrepreneurship of resource-based theory', Journal of Management, 27, 755-775. 
Amit, R. and Zott, C. (2001) 'Value creation in e-business', Strategic Management Journal, 22(6-7), 493-520.

Armstrong, L. and Hagel, J. (1996) 'The real value of on-line communities', Harvard Business Review, 74(3), 134-141.

Babbie, E. (1999) The basics of social research, Melbourne, Wadsworth Publishing Company.

Baker, W.E. and Sinkula, J.M. (2002) 'Market orientation, learning orientation and product orientation: Delving into the organization's black box', Journal of Market-Focused Management, 5, 5-23.

Brandenburger, A. M. and Nalebuff, B. J. (1995) 'The right game: Use game theory to shape strategy’, Harvard Business Review, 73(4), 57-71.

Carson, D. (1998) 'The marketing-entrepreneurship interface: A critique and some pragmatic alternatives for marketing managers’, Irish Marketing Review, 11(1), 49-58.

Chappell, C. and Feindt, S. (1999) 'Analysis of e-commerce practice in SMEs', http://www.kite.tsa.de/, Accessed on 12/9/2001.

Chaston, I., Badger, B., Mangles, T. and Sadler-Smith, E. (2001) 'The Internet and ecommerce: An opportunity to examine organisational learning in progress in small manufacturing firms’, International Small Business Journal, 19(2), 134-147.

Chau, S. and Pedersen, S. (2000) Small is beautiful: The emergence of new micro business utilising electronic commerce, Proceedings of the Eleventh Australasian Conference on Information Systems, Brisbane, School of Information Systems, University of Tasmania.

Cohen, W.M. and Levinthal, D.A. (1990) 'Absorptive capacity: A new perspective on learning and innovation’, Administrative Science Quarterly, 35, 128-152.

Collinson, E. and Shaw, E. (2001) 'Entrepreneurial marketing - a historical perspective on development and practice’, Management Decision, 39(9), 761-766.

Connor, T. (1999) 'Customer-led and market-oriented: A matter of balance', Strategic Management Journal, 20(12), 1157-1163.

Day, G.S. (1999) ‘Creating a market-driven organisation’, Sloan Management Review, 41(1), 23-34.

Drucker, P.F. (1985) Innovation and entrepreneurship, New York, Harper and Row.

Enders, A. and Jelassi, T. (2000) 'The converging business models of Internet and bricksand-mortar retailers’, European Management Journal, 18(5), 542-550.

Gare, S. (2001) Herded, bossed and cajoled, then milked, The Australian, 14/7/2001. 
Glazer, R. (1991) 'Marketing in an information intensive environment: Strategic implications of knowledge as an asset', Journal of Marketing, 55, 1-19.

Hamel, G. and Prahalad, C.K. (1994) Competing for the future, Boston, Harvard Business School Press.

Hamill, J. (1997) 'The Internet and international marketing', International Marketing Review, 14(5), 300-323.

Hertzberg, F. (1966) Work and the nature of man, Cleveland, World Publishing.

Hoffman, D. L. and Novak, T. P. (1997) 'A new marketing paradigm for electronic commerce’, The Information Society, 13(1), 43-55.

Hunt, S.H. and Morgan, R.M. (1995) 'The comparative advantage theory of competition', Journal of Marketing, 59(April), 1-15.

Kirzner, I. (1979) Perception, opportunity, and profit, Chicago, University of Chicago Press.

Kotler, P. (1997) Marketing management: The Millennium edition, Sydney, Prentice Hall.

Lado, A.A., Boyd, N.G. and Hanlon, S.C. (1997) 'Competition, cooperation, and the search for economic rents: A syncretic model', Academy of Management Review, 22(1), 110-141.

Lodish, L.M., Morgan, H.L. and Kallianpur, A. (2001) Entrepreneurial marketing, Brisbane, John Wiley \& Sons.

McLennan, W. (1999) Small business in Australia, ABS Catalogue No. 1321.0.

McWilliams, A. and Gray, S.R. (1995) 'Understanding quasi integration', Journal of Business Strategies, 11, 171-195.

Min, S., Song, S. and Keebler, J.S. (2002) 'An Internet-mediated market orientation (IMO): Building a theory’. Journal of Marketing Theory and Practice, 10(2), 1-11.

Mintzberg, H. (1990) 'The Design School: Reconsidering the basic premises of strategic management’, Strategic Management Journal, 11(3), 175-195.

Morgan, R.E., Katsikeas, C.S. and Appuh-Adu, K. (1998) 'Market orientation and organisational learning’, Journal of Marketing Management, 14, 353-381.

Pelham, A.M. and Wilson, D. (1996) 'A longitudinal study of the impact of market structure, and market orientation culture on dimensions of small-firm performance', Journal of the Academy of Marketing Science, 24(1), 27-43.

Peterson, R.T. (1989) 'Small business adoption of the marketing concept vs. other business strategies’, Journal of Small Business Management, 27(1), 38-46.

Plume, H. (2001) Survival of the e-fittest, www.capcollege.bc.ca/admin/Formedia/2001releases/ebiz.html, Accessed on 5/8/2001. 
Poon, S. and Strom, J. (1997) An Australia-UK study of small firm internet use, Proceedings of the 1997 International Management Development Association Conference, Seoul, Korea, 316-323.

Poon, S. and Swatman, P.M.C. (1999) 'An exploratory study of small business Internet commerce issues’, Information \& Management, 35, 9-18.

Porter, M.E. (1985) Competitive advantage, New York, Free Press.

Prahalad, C.K. and Hamel, G. (1990) ‘The core competence of the corporation', Harvard Business Review, 68(3), 79-91.

Rayport, J. F. and Jaworski, B. J. (2001) e-Commerce, Sydney, McGraw-Hill/Irwin.

Rogers, E.M. (1995) Diffusion of innovations, $4^{\text {th }}$ edition, New York, The Free Press.

Rouse, M.J. and Daellenbach, U.S. (1999) 'Rethinking research methods for the resourcebased perspective: Isolating sources of sustainable competitive advantage', Strategic Management Journal, 20(5), 487-494.

Sawhney, M. and Zabin, J. (2001) The seven steps to nirvana, Sydney, McGraw-Hill.

Sanchez, R. (1997) 'Preparing for an uncertain future: Managing for strategic flexibility', International Studies of Management \& Organisation, 27(2), 71-95.

Shane, S. and Venkataraman, S. (2000) 'The promise of entrepreneurship as a field of research’, Academy of Management Review, 25(1), 217-226.

Slater, S.F. (2001) 'Market orientation at the beginning of a new millennium', Managing Service Quality, 11(4), 230-232.

Slater, S.F. and Narver, J.C. (1994) 'Does competitive environment moderate the market orientation performance relationship,' Journal of Marketing, 58(January), 46-55.

Slater, S.F. and Narver, J.C. (1995) 'Market orientation and the learning organization', Journal of Marketing, 59(July), 63-74.

Slater, S.F. and Narver, J.C. (1998) 'Customer-led and market-oriented: Let's not confuse the two’, Strategic Management Journal, 19(10), 1001-1006.

Stokes, D. (2000) 'Entrepreneurial marketing: A conceptualisation from qualitative research', Qualitative Market Research: An International Journal, 3(1), 47-54.

Timmers, P. (1998) ‘Business models for electronic markets’, Electronic Markets, 8(2), 3-8, www.electronicmarkets.org, Accessed on 2/6/2001.

Wrenn, B. (1997) Reality based market orientation, Proceeding of Marketing Management Association, Chicago, IL: Marketing Management Association and Department of Marketing, School of Business, Indiana State University. 
Yellow Pages Business Index, (2001) E-commerce and computer technology, http://www.corporate.pacificaccess.com.au, Accessed on 13/9/2001.

Yin, R.K. (1994) Case study research design and methods, $2^{\text {nd }}$ edition, Thousand Oaks, California, Sage Publications.

Zahra, S.A. and George, G. (2002) 'Absorptive capacity: A review, reconceptualization, and extension’, Academy of Management Review, 27(2), 185-203. 
Figure 1: Normative Web-based Commerce Adoption Model

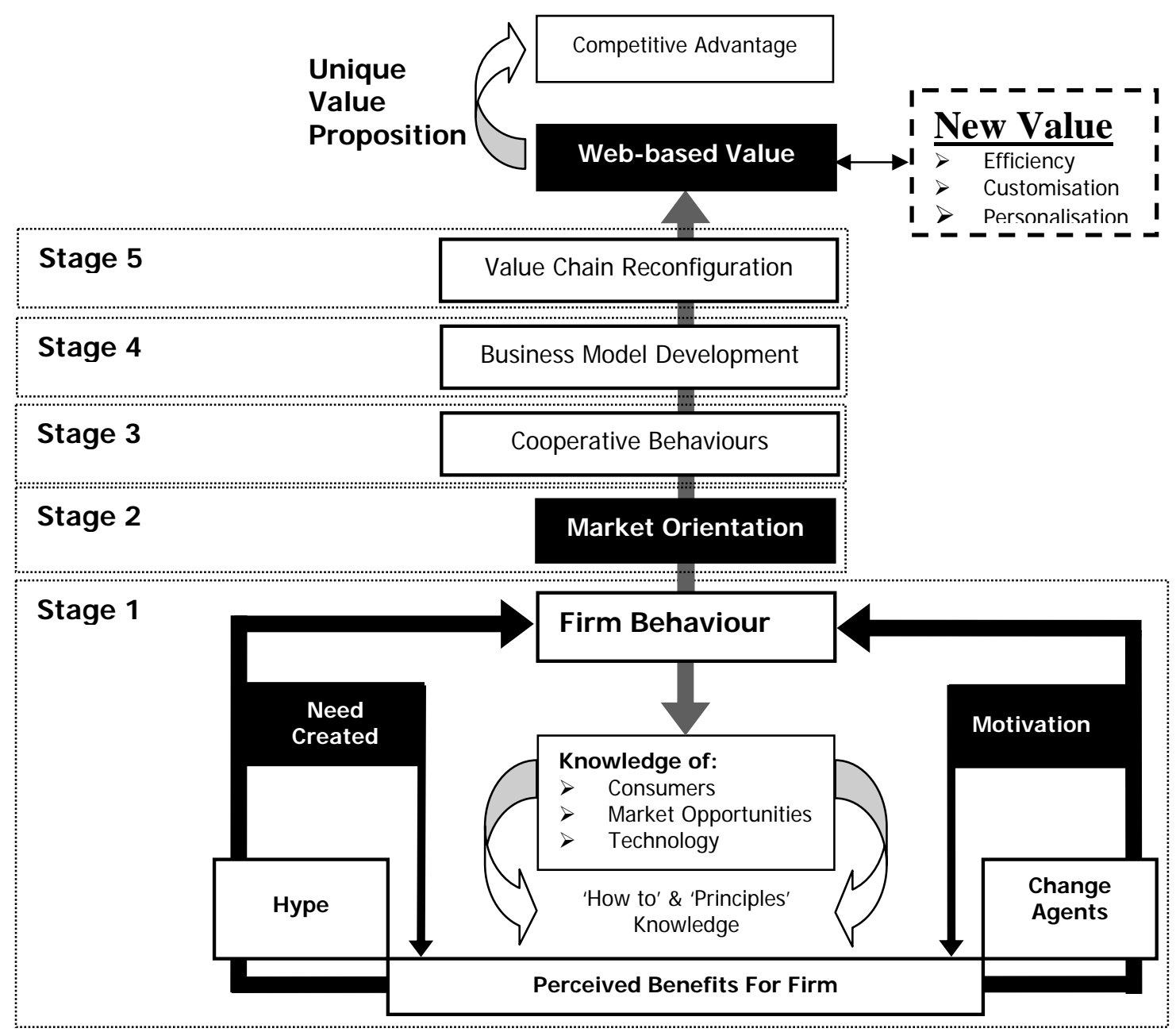


Table 1: Description of Firms

\begin{tabular}{|c|c|c|c|c|c|}
\hline & Firm A & Firm B & Firm C & Firm D & Firm E \\
\hline Industry & $\begin{array}{c}\text { Book } \\
\text { Publishing } \\
\end{array}$ & $\begin{array}{l}\text { Children's } \\
\text { Footwear }\end{array}$ & Winemaker & $\begin{array}{l}\text { Whiskey } \\
\text { Distiller }\end{array}$ & $\begin{array}{c}\text { Knitwear } \\
\text { Manufacturer }\end{array}$ \\
\hline Adoption Year & 1996 & 1997 & 1998 & 1995 & 1998 \\
\hline Initial Motivation & Change Agent & Change Agent & Change Agent & Hype & Hype \\
\hline $\begin{array}{l}\text { Traditional } \\
\text { Market Orientation }\end{array}$ & 4.56 & 4.11 & 4.33 & 4.11 & 4.89 \\
\hline $\begin{array}{l}\text { Web-based } \\
\text { Market Orientation }\end{array}$ & 3.56 & 4.22 & 3.11 & 3.56 & 4.78 \\
\hline Difference & $-22.00 \%$ & $2.70 \%$ & $-28.00 \%$ & $-16.00 \%$ & $-2.25 \%$ \\
\hline
\end{tabular}

